\title{
First Record of a Rare Sandperch, Parapercis fuscolineata, from Southern Japan (Actinopterygii: Perciformes: Pinguipedidae)
}

\author{
Naohide Nakayama ${ }^{1,3,4}$, Toshiyuki Ohkawa ${ }^{2}$, and Hiromitsu Endo ${ }^{1}$ \\ ${ }^{1}$ Laboratory of Marine Biology, Faculty of Science, Kochi University, 2-5-1 Akebono-cho, Kochi 780-8520, Japan \\ E-mail: gadiformes@gmail.com \\ ${ }^{2}$ Kochi Prefectural Fisheries Experimental Station, 1153-23 Uranouchi-Haikata, Susaki, Kochi 785-0167, Japan \\ ${ }^{3}$ Present address: The Kyoto University Museum, Kyoto University, Yoshida, Sakyo, Kyoto 606-8501, Japan \\ ${ }^{4}$ Corresponding author
}

(Received 11 September 2015; Accepted 13 April 2016)

\begin{abstract}
A rare sandperch, Parapercis fuscolineata Fourmanoir, 1985, is reported for the first time from Japan, based on a single specimen (36.8 mm SL) collected from Tosa Bay, Kochi Prefecture, Shikoku Island, at a depth of 200-203 m. This species was previously known only from the Philippines (type locality) and the tropical southwest Pacific region (Solomon Islands, Vanuatu, and New Caledonia); thus the Japanese specimen represents the northernmost record of the species. The unique coloration of $P$. fuscolineata, including a dark continuous stripe extending from the hind rim of the orbit to the caudal peduncle, a large black ocellus on the upper caudal-fin base, and about 12 diagonal yellowish bars on the lower half of the body, readily distinguishes this species from its congeners. The Japanese specimen is fully described, with color photographs of the fresh specimen. A new Japanese name, "Kuroobi-toragisu”, is proposed for P. fuscolineata.
\end{abstract}

Key Words: Teleostei, distribution, range extension, Tosa Bay, Kochi Prefecture, Japan, northwestern Pacific.

\section{Introduction}

The sandperch genus Parapercis Bleeker, 1863 is by far the most diverse group of the perciform family Pinguipedidae, with about 80 species currently regarded as valid (Randall 2008; Ho et al. 2014; Ho 2015). Parapercis fuscolineata was originally described by Fourmanoir (1985) based on four specimens collected in the South China Sea off the Lubang Islands, the Philippines. The original description is brief, although it includes an excellent drawing with a short description of the species' unique coloration. Recently, Ho (2015) provided a redescription of P. fuscolineata based on two paratypes and three additional specimens from the tropical southwest Pacific region. During a bottom trawl survey conducted by the Kochi Prefectural Fisheries Experimental Station, a single specimen of Parapercis was collected from Tosa Bay, Kochi Prefecture, Shikoku Island, Japan, at a depth of 200-203 m. Further examination revealed that it represents the first record of $P$. fuscolineata from Japan and the northernmost record of the species.

\section{Materials and Methods}

Methods for taking counts and making measurements follow Randall et al. (2008) and Ho (2015). The standard and head lengths are expressed as SL and HL respectively. The terminology of the cephalic lateralis system follows Carton and Montgomery (2004). The specimen examined here is deposited in the Laboratory of Marine Biology, Faculty of Science, Kochi University (BSKU). Institutional codes follow Fricke and Eschmeyer (2016).

Parapercis fuscolineata Fourmanoir, 1985

[New standard Japanese name: Kuroobi-toragisu]

(Figs 1-2, Table 1)

Parapercis fuscolineata Fourmanoir, 1985: 36, fig. 1 (original description; 4 specimens; type locality: South China Sea off Lubang Islands, Philippines, 170-187 m depth; holotype lost; 2 extant paratypes: MNHN 1984-430 and BPBM 29668); Randall 2001: 3505 (in key); Ho 2015: 265, fig. 4 (redescription; 3 additional specimens; southwestern Pacific, 180-355 $\mathrm{m}$ depth).

Material examined. BSKU 119364, 1 specimen, $36.8 \mathrm{~mm}$ SL, Tosa Bay off mouth of Niyodo River, Kochi Prefecture, Shikoku Island, Japan, $33.2424^{\circ} \mathrm{N}, 133.6312^{\circ} \mathrm{E}, 200-203 \mathrm{~m}$ depth, bottom temperature $13.4^{\circ} \mathrm{C}, \mathrm{R} / \mathrm{V}$ Tosa-kaiyo-maru, otter trawl, collected by T. Ohkawa, time 11:52-12:07, 11 August 2015.

Diagnosis. [Modified from Ho (2015).] Species of Parapercis with dark continuous stripe extending from hind rim of orbit to caudal peduncle, ending with large, black ocellus on upper caudal-fin base; spinous portion of dorsal fin uniformly dark; about 12 diagonal yellowish bars on lower half of body; dorsum above dark horizontal stripe uniformly dusky yellow; HL 25.8-30.4\% SL; snout length 5.9-7.8\% SL; orbit diameter 9.5-13.2\% SL; interorbital 


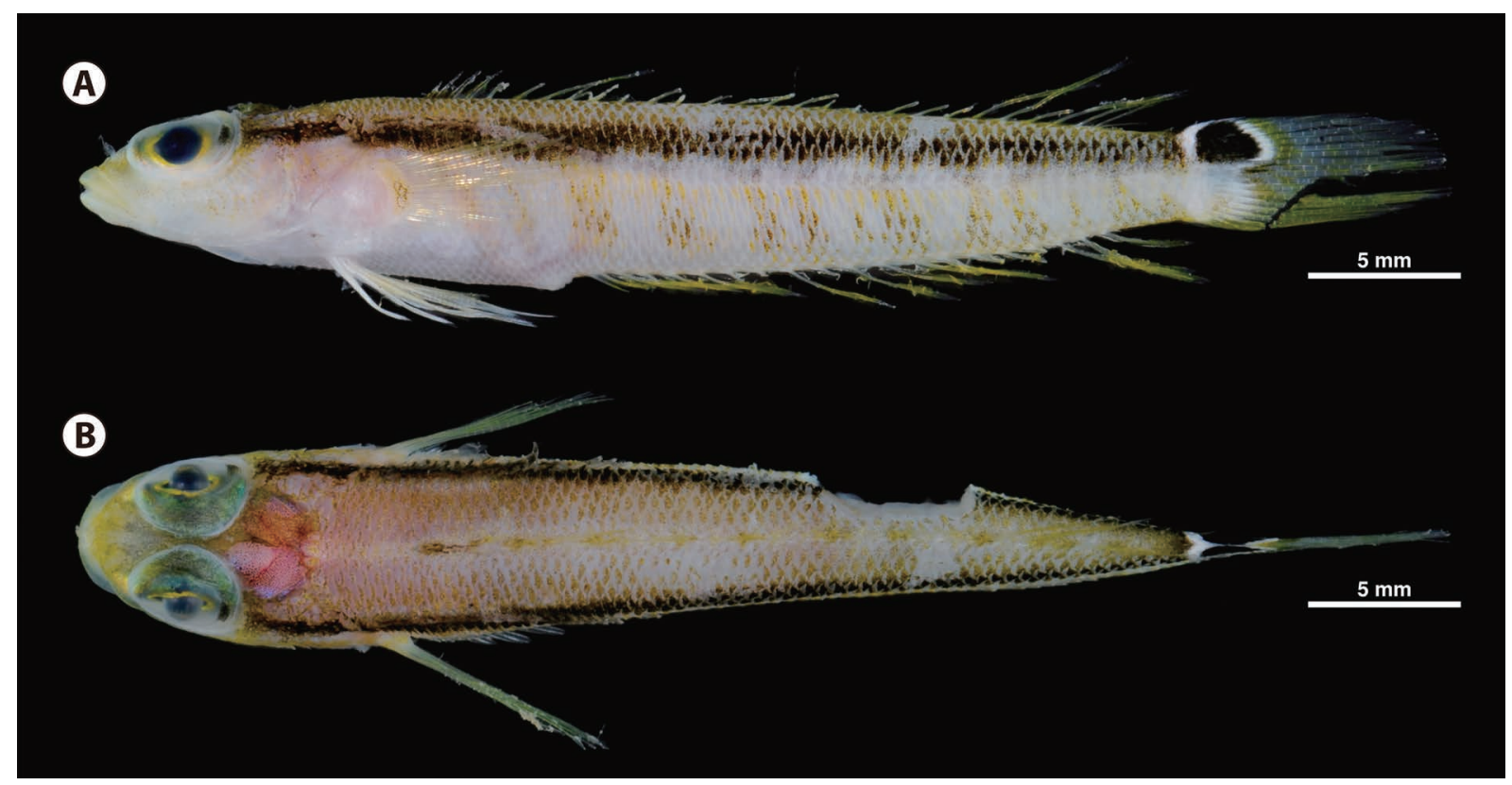

Fig. 1. Fresh coloration of Parapercis fuscolineata. BSKU 119364, $36.8 \mathrm{~mm}$ SL, Tosa Bay off mouth of Niyodo River, Kochi Prefecture, Shikoku Island, Japan, 200-203 m depth. A, lateral view; B, dorsal view.

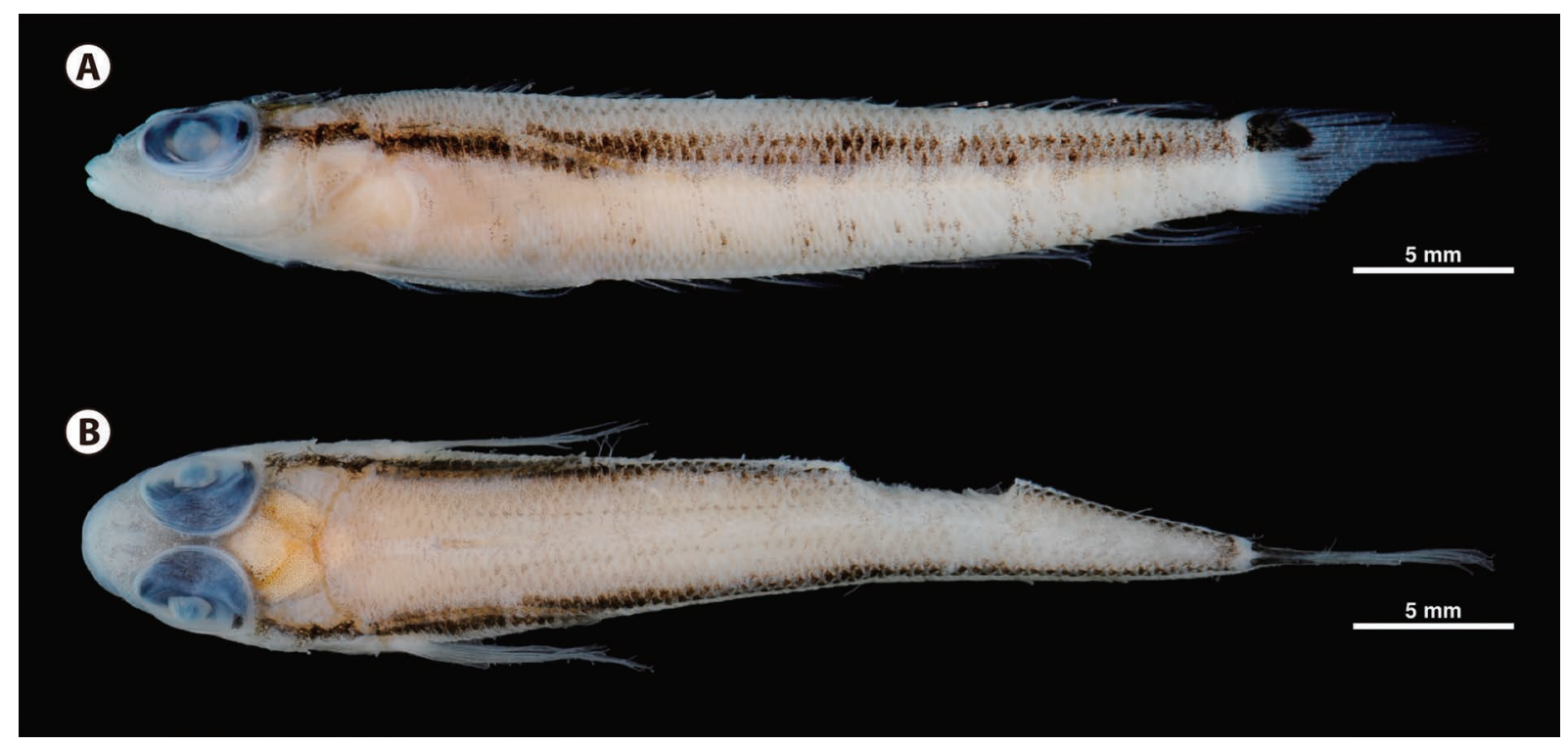

Fig. 2. Preserved specimen of Parapercis fuscolineata. BSKU 119364, $36.8 \mathrm{~mm}$ SL, Tosa Bay off mouth of Niyodo River, Kochi Prefecture, Shikoku Island, Japan, 200-203 m depth. A, lateral view; B, dorsal view.

width $1.4-1.9 \%$ SL; four pairs of enlarged canines at tip of lower jaw; vomerine teeth in 1-2 rows, forming broadly Vshaped patch; palatine teeth in 1-2 rows on each side; dorsal-fin rays IV-V, 23; dorsal-fin spines gradually increasing in height posteriorly; anal-fin rays I, 19; pectoral-fin rays 17-19; pored lateral-line scales 61-63; transverse scale rows between dorsal-fin origin and lateral line 3.5-4.5; total gill rakers on first arch 12-20.

Description of Japanese specimen. General features shown in Figs 1 and 2. Counts and measurements given in Table 1.

Dorsal fin long-based, origin slightly behind vertical drawn through pectoral-fin base; first spine short, thin; height of spines progressively increasing posteriorly (membrane between spinous and soft portions broken); intact soft rays branched, 18th longest (most rays heavily damaged). Anal fin long-based, origin below base of fifth dorsal-fin soft ray; intact soft rays branched, 17th longest. Pectoral fin well developed; all rays branched except for uppermost and lowermost few rays; tip of pectoral fin extending posteriorly to below base of sixth dorsal-fin soft ray. Pelvic fin inserted below opercle, its tip extending slightly beyond anus when laid back. Caudal fin truncate.

Body elongate, almost uniformly shallow, depth at pec- 
Table 1. Measurements and counts for Parapercis fuscolineata.

\begin{tabular}{|c|c|c|c|}
\hline & \multirow{2}{*}{$\begin{array}{c}\text { This study } \\
\text { BSKU } 119364 \\
n=1\end{array}$} & \multicolumn{2}{|c|}{ Ho (2015) } \\
\hline & & $\begin{array}{c}\text { Paratypes } \\
n=2\end{array}$ & $\begin{array}{c}\text { Non-types } \\
n=3\end{array}$ \\
\hline \multicolumn{4}{|l|}{ Measurements } \\
\hline SL & 36.8 & $62.5-76.1$ & $34.9-114.0$ \\
\hline \multicolumn{4}{|l|}{$\%$ of SL } \\
\hline $\mathrm{HL}$ & 28.1 & $27.2-27.5$ & $25.8-30.4$ \\
\hline Body depth at pectoral-fin base & 15.6 & $13.3-15.8$ & $12.3-15.0$ \\
\hline Body width over pectoral-fin bases & 17.7 & $15.8-16.8$ & $16.3-18.2$ \\
\hline Snout length & 6.6 & $5.9-6.4$ & $6.0-7.8$ \\
\hline Orbit diameter & 10.5 & $9.7-9.9$ & $9.5-13.2$ \\
\hline Interorbital width & 1.9 & $1.4-1.7$ & $1.6-1.7$ \\
\hline Upper-jaw length & 9.5 & $8.8-9.9$ & $9.6-10.3$ \\
\hline Predorsal-fin length & 32.2 & $30.9-31.3$ & $27.7-33.5$ \\
\hline Prepelvic-fin length & 24.4 & $24.2-24.7$ & $25.7-28.6$ \\
\hline Preanal-fin length & 46.4 & $45.9-46.1$ & $43.6-50.1$ \\
\hline Dorsal-fin base length & 60.5 & $61.1-61.9$ & $62.2-64.8$ \\
\hline 1st dorsal-fin spine length & 1.4 & $?-3.0$ & $1.1-1.5$ \\
\hline 2nd dorsal-fin spine length & 2.4 & $?-4.6$ & 3.0 \\
\hline 3rd dorsal-fin spine length & 4.0 & $5.9-7.9$ & $4.8-5.0$ \\
\hline 4th dorsal-fin spine length & 4.2 & $6.9-8.5$ & $6.1-6.5$ \\
\hline 5th dorsal-fin spine length & 5.4 & Absent & $6.4-6.9$ \\
\hline Length of longest dorsal-fin ray & 13.9 & $12.0-12.6$ & $12.3-13.9$ \\
\hline Anal-fin base length & 47.3 & $40.2-45.6$ & $42.1-49.2$ \\
\hline Anal-fin spine length & 4.4 & $2.4-5.3$ & $2.6-4.9$ \\
\hline Length of longest anal-fin ray & 12.5 & $12.6-13.0$ & $11.8-12.6$ \\
\hline Pectoral-fin length & 22.4 & $19.7-21.9$ & $19.9-23.5$ \\
\hline Pelvic-fin length & 21.5 & $19.8-20.0$ & $18.6-21.5$ \\
\hline Pelvic-fin spine length & 7.8 & $6.4-7.4$ & $7.1-8.0$ \\
\hline Caudal-fin length & 22.7 & $20.6-21.0$ & $17.8-23.2$ \\
\hline Caudal peduncle length & 8.1 & $6.6-7.8$ & $6.6-9.0$ \\
\hline Caudal peduncle depth & 8.1 & $7.8-8.4$ & $8.2-8.3$ \\
\hline \multicolumn{4}{|l|}{ Counts } \\
\hline Dorsal-fin rays & $\mathrm{V}, 23$ & IV, 23 & $\mathrm{~V}, 23$ \\
\hline Anal-fin rays & I, 19 & I, 19 & I, 19 \\
\hline Pectoral-fin rays & 17 & 18 & $17-19$ \\
\hline Principal caudal-fin rays & 18 & $17-19$ & 17 \\
\hline Pored lateral-line scales & 61 & $61-63^{*}$ & 60 or 61 \\
\hline Median predorsal scales & 9 & 9 & 8 or 9 \\
\hline Scale rows above lateral line & 4.5 & $3.5-4.5$ & 4 or 4.5 \\
\hline Scale rows below lateral line & 11 & ca. 12 & 12 \\
\hline Circumpeduncular scales & 18 & 18 & 21 or 22 \\
\hline Pseudobranchial filaments & Broken & 11 & $10-15$ \\
\hline Gill rakers & $4+9=13$ & $5-7+10-13=15-20$ & $4-5+8-10=12-14$ \\
\hline
\end{tabular}

* 63 or 61 in MNHN 1984-430, 61 in BPBM 29668

toral-fin base $88 \%$ of width over pectoral-fin bases; body cylindrical anteriorly, progressively compressed posteriorly. Head small, rounded, HL $28 \%$ of SL. Snout short, moderately pointed in lateral view but broadly rounded in dorsal view; snout length $23 \%$ of HL. Orbit large, oval, its horizontal diameter $37 \%$ of HL. Interorbital space very narrow, $7 \%$ of HL. Mouth small, terminal; upper jaw length $34 \%$ of HL; maxilla oblique, forming angle of about $30^{\circ}$ to horizontal axis of head and body; posterior end of maxilla reaching about to vertical drawn through anterior margin of pupil; tips of upper and lower jaws about on same vertical; lips thick, fleshy. Opercle with long, stout, horizontal spine on its dorsal margin; subopercle with similar strong spine at posteroventral corner; preopercle broadly rounded posteroventrally, its free margin extending from level of opercular spine to below hind margin of pupil; preopercle and interopercle smooth along their free margins. Gill membranes broadly united, with broad posterior free fold, not attached to isthmus. Branchiostegal rays six. Gill rakers short, ridgelike; pseudobranchial filaments broken (at least eight on left side). Caudal peduncle short, its length and depth $29 \%$ of HL.

Teeth small, conical, slender, slightly incurved, in broad tapered band in both jaws. Three pairs of prominent canines 
at tip of premaxillary, followed laterally by single row of 18 much smaller teeth, these decreasing in height posteriorly (16 on right side); broad inner band of small, villiform teeth anteriorly, this band gradually tapering posteriorly with about 4-5 tooth rows at widest point near symphysis. Four pairs of prominent canines at tip of dentary, followed laterally by single row of 13 conical teeth, these gradually increasing in height posteriorly (11 on right side), this row followed posteriorly by single row of nine uniformly small teeth; broad inner band of small, villiform teeth anteriorly, this band abruptly narrowing posteriorly, with about 3-4 tooth rows near symphysis. Vomer with single row of small, stout, conical teeth forming broadly V-shaped tooth patch. Palatine teeth similar to those on vomer, arranged in one distinct row on each side.

Anterior nostril modified into long tube, slightly shorter than first spine of dorsal fin, with its base situated on horizontal drawn through midorbit when viewed laterally. Posterior nostril small, oval, located dorsoposteriorly to anterior nostril, simple with no fleshy fringe along its edge. Internarial width about twice length of anterior nostril tube.

Cephalic lateralis system with many open pores along sensory canals. Supraorbital canal with seven pores: one behind snout tip, one lateral to anterior nostril, one above posterior nostril, one between both nostrils, and three along upper rim of orbit. Infraorbital canal well developed, with about nine lower branches; three pores serially arranged above upper jaw; 10 pores along posteroventral rim of orbit (12 on right side); several pores scattered over cheek. Mandibular canal with five pores along lower jaw; pair of small pores on chin. Preopercular canal with about eight anterodorsal branches; six pores along main canal; each branch with single pore terminally. Nape and postorbital region heavily damaged; at least six pores along otic canal.

Scales totally missing from head and body surfaces, except for a few remaining behind paired fins, beneath gill covers, and along lateral line and anal-fin base. Most of these scales small, thin, highly deciduous, covered with short, reclined, needle-like spinules along their hind margin; scales beneath gill covers lacking spinules. Predorsal scaled area extending to slightly behind line connecting posterior margins of preopercles. Head naked, except for cheek behind lateral corner of mouth. Postorbital area narrowly scaled above dark horizontal stripe on head. All fins naked, but caudal fin heavily scaled basally.

Lateral line broadly arched over pectoral fin, then gradually descending to become straight posterior to vertical drawn through anal-fin origin.

Color when fresh (Fig. 1). Prominent dark stripe about two scales deep extending from hind rim of orbit to caudal peduncle, ending with large, black ocellus on upper caudalfin base. Dorsum above dark stripe uniformly dark yellow. Ground color of lower 2/3 of body white. About 12 diagonal, dusky yellowish bars below mid-lateral axis of body: first and second on trunk behind pectoral fin, third at vertical drawn through anal-fin origin, 4th-11th above analfin base, and last on caudal peduncle; these diagonal bands not reaching dark horizontal stripe dorsally. Narrow yellow stripe about one scale deep extending mid-laterally from vertical drawn through anal-fin origin to caudal peduncle. Spinous portion of dorsal fin uniformly dark, soft portion yellowish (but heavily damaged). Pectoral fin translucent pale yellow; small dusky spot present on lower half of pectoral-fin base. Pelvic fin generally white, but soft portion with slightly yellowish tinge. Anal fin bright yellow, paler basally. Lower half of caudal-fin base white; about three faint yellowish bars on upper half of caudal fin, lower half uniformly yellow. Snout bright yellow, especially anteriorly. Small black spot on posterior portion of eye; pupil surrounded by yellow-gold iris; dorsal surface of eyes dark green. Nape pinkish orange. Upper jaw slightly yellow, lower jaw much paler. Opercle and pectoral girdle with slightly pinkish tinge. Underside of head generally white.

Color in 70\% ethanol (Fig. 2). Ground color of head and body white, with prominent dark stripe extending from hind rim of orbit to caudal peduncle, followed by large, black ocellus on upper caudal-fin base. Dorsum above dark stripe uniformly dusky. About 12 diagonal dark stripes on lower $2 / 3$ of body. Iris black, but narrowly pale along pupil; dorsal surface of eyes blackish. Oral and gill cavities uniformly white. Gill rakers, arches, and filaments cream. Fins uniformly paler, except for dark spinous portion of dorsal fin; caudal ocellus narrowly outlined in black posteriorly; pectoral-fin base somewhat dusky.

Distribution. Known from the Western Pacific from Japan to New Caledonia, including the South China Sea off the Philippines (type locality), Solomon Islands, and Vanuatu (Ho 2015; this study; Fig. 3). Depth range 170-355 m.

Remarks. Parapercis fuscolineata was originally described by Fourmanoir (1985) based on four specimens (54-78 mm SL) collected from the South China Sea off the Philippines. The holotype and a $54 \mathrm{~mm}$ SL paratype are now believed to be lost (Ho 2015).

The Japanese specimen agrees well with the original de-

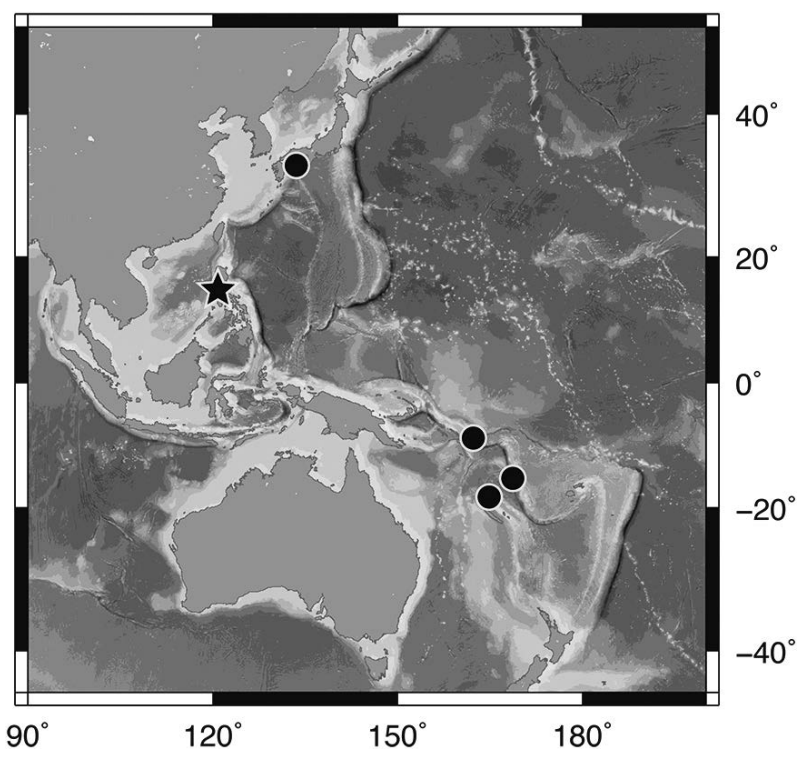

Fig. 3. Map showing the known distribution of Parapercis fuscolineata. The star indicates the type locality. 
scription of $P$. fuscolineata and a redescription given by Ho (2015), including the presence of a dark continuous stripe dorsally along the body, a large, black ocellus on the upper caudal-fin base, and about 12 diagonal yellowish bars below the mid-lateral axis of the body (Fig. 1). The combination of these prominent markings is unique to P. fuscolineata, and readily distinguishes this species from all its congeners. In addition, the spinous portion of the dorsal fin is uniformly dark in all known specimens, and this consistent feature appears to further characterize the species (Ho 2015; this study).

Although the original description of $P$. fuscolineata is brief, it includes an excellent drawing of a $78 \mathrm{~mm}$ SL paratype, with an adequate description of the fresh coloration (Fourmanoir 1985: 36, fig. 1). The color pattern of the Japanese specimen agrees well with that described by Fourmanoir (1985), except that the dark stripe on the body originates at the hind rim of the orbit ( $v s$ "origin of opercle"). However, Fourmanoir's description is not accurate; Ho (2015) confirmed that the dark stripe of the type specimens actually originates behind the orbit. According to Fourmanoir (1985), a narrow white stripe runs dorsally along the dark stripe. However, the dorsum above the dark stripe is uniformly dusky in the Japanese specimen. This discrepancy is likely due to the specimens' size difference (SL 54-78 $\mathrm{mm}$ in the types $v s 36.8 \mathrm{~mm}$ in the Japanese specimen).

Counts and measurements of the Japanese specimen generally lie within (or only slightly outside) the range of variation of P. fuscolineata given by Ho (2015), except for the relatively much shorter dorsal-fin spines (third spine $4.0 \% \mathrm{SL}$ in the Japanese specimen $v s$ 4.8-7.9\%; fourth spine $4.2 \%$ vs 6.1-8.5\%; fifth spine 5.4\% SL vs 6.4-6.9\%; Table 1). The Japanese specimen differs slightly from Ho's (2015) redescription in that the tips of both jaws extend forward to the same vertical ( $v s$ the lower jaw protruding slightly beyond the upper jaw). Further differences are obvious in the dentition, with the Japanese specimen having much narrower inner bands, viz., inner premaxillary teeth in about $4-5$ series at the widest point near the symphysis ( $v s c a$. eight series), and those of the dentary in about 3-4 series anteriorly ( $v s$ 7-8 series). The Japanese specimen also differs from Ho's (2015) redescription in that the vomer and palatines are each covered with a single tooth row ( $v s$ two rows). Unfortunately, $P$. fuscolineata is poorly represented in museum collections, and there is little knowledge of its morphological variation. The differences highlighted here could be attributed to ontogenetic variation, but it should be noted that Ho (2015) examined a juvenile (NMHN 2000-5541, $34.9 \mathrm{~mm} \mathrm{SL}$ ) that is almost equal in size to the Japanese specimen.

Ho (2015) indicated several differences in the counts and coloration between the types and the tropical southwest Pacific specimens of $P$. fuscolineata, and suggested that the latter may represent an undescribed species. According to Ho (2015), these specimens differ from the two paratypes he examined in having higher counts of dorsal-fin spines (five $v s$ four) and circumpeduncular scales (21-22 vs 18) and lower counts of gill rakers (total 12-14 vs 15-20). The Japanese specimen agrees with the paratypes in having 18 circum- peduncular scales whereas it matches the tropical southwest Pacific specimens in having five dorsal-fin spines and 13 gill rakers. Ho (2015) also noted that the body stripe of a juvenile from New Caledonia (NMHN 2000-5541, $34.9 \mathrm{~mm}$ SL) did not fade after a long time in preservative, although Fourmanoir (1985: 37) wrote that "the dark stripe is indistinct in a juvenile specimen and it disappears quickly in alcohol". The body stripe of the Japanese specimen is prominently dark in both fresh and preserved conditions (Figs $1-2)$. Due to the paucity of available material, it is impossible to provide a definitive conclusion on their conspecificity. A further in-depth study is necessary to confirm whether the species is widely distributed in the Western Pacific.

The occurrence of P. fuscolineata in Tosa Bay extends its known range approximately $2,600 \mathrm{~km}$ northward from the Philippines (Fig. 3). It brings the total number of Japanese sandperch species to 30 (Ogihara and Endo 2011; Hibino et al. 2013; Shimada 2013; this study). This species is not likely to be confused with other Japanese congeners due to its unique coloration. A new standard Japanese name, "Kuroobi-toragisu", is proposed here for P. fuscolineata based on the specimen BSKU 119364. This name is derived from the characteristic dark stripe of this species $(=$ kuroobi) and the Japanese name for sandperches (= toragisu).

\section{Acknowledgments}

We are grateful to the captain and crew of the R/V Tosakaiyo-maru of the Kochi Prefectural Fisheries Experimental Station for their assistance during the cruise. We also thank H.-C. Ho (NMMBP) for sharing his knowledge of sandperches; R. Misawa (FAKU) for providing references; and G. Yearsley (Hobart) for editing the English text. This study was partly supported by a Grant-in-Aid for Scientific Research (B) from the Japan Society for the Promotion of Science, Tokyo (24370041); a Grant-in-Aid of the "Marine Science Project" of the Natural Science Cluster, Science Unit, Kochi University; and the "Kuroshio Sougou Project" of the National Museum of Nature and Science, Tsukuba.

\section{References}

Carton, A. G. and Montgomery, J. C. 2004. A comparison of lateral line morphology of blue cod and torrentfish: two sandperches of the family Pinguipedidae. Environmental Biology of Fishes 70: 123131.

Fourmanoir, P. 1985. Poissons. Liste et description de cinq espèces nouvelles (MUSORSTOM II). Mémoires du Muséum National d'Histoire Naturelle, Série A (Zoologie) 133: 31-54.

Fricke, R. and Eschmeyer, W. N. 2016. A guide to fish collections in the Catalog of Fishes. Available at http://researcharchive.calacademy. org/research/ichthyology/catalog/collections.asp (5 January 2016).

Hibino, Y., Motomura, H., and Kimura, S. 2013. First record of the sandperch (Perciformes: Pinguipedidae) Parapercis randalli from Yoron-jima Island, Kagoshima Prefecture, Japan. Japanese Journal of Ichthyology 60: 129-134. [In Japanese with English abstract]

Ho, H.-C. 2015. Description of a new species and redescriptions of two 
rare species of Parapercis (Perciformes: Pinguipedidae) from the tropical Pacific Ocean. Zootaxa 3999: 255-271.

Ho, H.-C., Heemstra, P. C., and Imamura, H. 2014. A new species of the sandperch genus Parapercis from the western Indian Ocean (Perciformes: Pinguipedidae). Zootaxa 3802: 335-345.

Ogihara, G. and Endo, H. 2011. Records of Parapercis lutevittata (Trachinoidei: Pinguipedidae) from off Shibushi, Kagoshima Prefecture, southern Kyushu, Japan. Bulletin of the Biogeographical Society of Japan 66: 261-266. [In Japanese with English abstract]

Randall, J. E. 2001. Family Pinguipedidae (= Parapercidae, Mugiloididae). Pp. 3501-3510. In: Carpenter, K. E. and Niem, V. H. (Eds) Species Identification Guide for Fishery Purposes. The Living Marine Resources of the Western Central Pacific, Volume 6. Bony Fishes
Part 4 (Labridae to Latimeriidae), Estuarine Crocodiles, Sea Turtles, Sea Snakes and Marine Mammals. FAO, Rome.

Randall, J. E. 2008. Six new sandperches of the genus Parapercis from the Western Pacific, with description of a neotype for P. maculata (Bloch \& Schneider). The Raffles Bulletin of Zoology Supplement 19: 159-178.

Randall, J. E., Senou, H., and Yoshino, T. 2008. Three new pinguipedid fishes of the genus Parapercis from Japan. Bulletin of the National Museum of Nature and Science, Series A (Zoology) Supplement 2: 69-84.

Shimada, K. 2013. Pinguipedidae. Pp. 1258-1264, 2088-2091. In: Nakabo, T. (Ed.) Fishes of Japan with Pictorial Keys to the Species, Third Edition. Tokai University Press, Hadano. [In Japanese] 